\title{
PSYCHOMETRIC PROPERTIES OF THE POLISH VERSION OF THE JOB-RELATED AFFECTIVE WELL-BEING SCALE
}

\section{BEATA A. BASIŃSKA ${ }^{1}$, EWA GRUSZCZYŃSKA ${ }^{2}$, and WILMAR B. SCHAUFELI ${ }^{3,4}$}

${ }^{1}$ Gdansk University of Technology, Gdańsk, Poland

Faculty of Management and Economics

${ }^{2}$ University of Social Sciences and Humanities, Warszawa, Poland

Faculty of Psychology

${ }^{3}$ Utrecht University, Utrecht, The Netherlands

Department of Psychology

${ }^{4}$ Catholic University of Leuven, Leuven, Belgium

Department of Psychology

\begin{abstract}
Objectives: The aim of this study was to verify psychometric properties of the Polish version of the Job-related Affective Well-being Scale (JAWS). Specifically, theoretical 4-factor structure (based on the dimensions of pleasure and arousal) and reliability of the original - 20-item JAWS (van Katwyk et al., 2000) and the shortened - 12-item (Schaufeli and Van Rhenen, 2006) versions were tested. Material and Methods: Two independent samples were analyzed (police officers, $\mathrm{N}=395$, and police recruits, $\mathrm{N}=202$ ). The Polish version of the original, 20-item, JAWS was used to measure job-related affective states across the past month (van Katwyk et al., 2000). This version of JAWS includes 2 dimensions: valence and arousal, which allow to assess 4 categories of emotions: low-arousal positive emotions, high-arousal positive emotions, lowarousal negative emotions and high-arousal negative emotions. Results: The results of multidimensional scaling analysis showed that the theoretical circumplex model of emotions underlining JAWS was satisfactorily reproduced. Also the hypothesized 4-factor structure of the Polish version of JAWS was confirmed. The 12-item version had better fit with the data than the original, 20-item, version, but the best fit was obtained for the even shorter, 8-item version. This version emerged from a multidimensional scaling of the 12 -item version. Reliabilities of the 20 - and 12 -item versions were good, with lower values for the 8-item JAWS version. Conclusions: The findings confirmed satisfactory psychometric properties of both Polish versions of the Job-related Affective Well-being Scale. Thus, when both psychometric properties and relevance for cross-cultural comparisons are considered, the 12-item JAWS is recommended as a version of choice.
\end{abstract}

Key words:

Well-being, Job-related affective well-being scale, Arousal, Circumplex of emotions, Multidimensional scaling, Confirmatory factor analysis

Received: April 11, 2014. Accepted: July 18, 2014.

Corresponding author: B.A. Basińska, Gdansk University of Technology, Faculty of Management and Economics, Narutowicza 11/12, 80-233 Gdańsk, Poland (e-mail: bbas@pg.gda.pl). 


\section{INTRODUCTION}

In recent years, research in the field of organizational psychology has increasingly emphasized the role of positive emotions. This contrasts with previous publications, which have focused mainly on negative affective states. Behind this shift of interest is an empirically validated observation that positive emotions also occur frequently during adverse events [1]. This is in line with the emerging field of positive psychology and its implementation in the area of organizational psychology. Occupational health and wellbeing have become associated not only with negative consequences such as burnout [2], but also with positive aspects such as engagement [3], as well as with positive and negative work behaviors [4]. It is against this background that the simultaneous assessment of negative and positive emotions should be viewed.

Though still relatively few methods in organizational psychology are investigated, interest in them is constantly growing [5]. Occupational stress assessment [6,7] has been the most popular of these. Also, a relatively small number of methods dedicated to the evaluation of emotional state at work has been put forward in literature [5]. Thus, in order to assess non-clinical samples in everyday work environment, there is a need for valid instruments that combine positive and negative aspects of work performance.

According to the approach of Russell and Carroll [8], that has been applied to the work context by Warr [4,9], all emotions are constituted by 2 dimensions: valence and arousal. The dimension of valence refers to the traditional distinction between positive and negative emotions (high-low pleasure), whereas the dimension of arousal describes emotions in terms of low versus high activation (high-low arousal). Accordingly, all human emotions can be plotted on the circumference of a circular space that is defined by 2 orthogonal dimensions: value and arousal. This is called the circumplex model of emotions.
The instrument that has been proposed for the study of emotions in the work context is the Job-related Affective Well-being Scale (JAWS) [10]. Originally, JAWS consists of 20 adjectives that describe various aspects of emotional well-being in relation to work in the past month. The 4-factor approach is characterized by positive and negative affect (dimension of valence), and high and low arousal (dimension of arousal).

The Job-related Affective Well-being Scale has some advantages in comparison with the Positive Affect and Negative Affect Scale (PANAS) [11], which is most frequently used to study affect. First, JAWS refers specifically to the occupational context. Second, the dimension of arousal was introduced alongside the dimension of valence. This way, JAWS includes not only the high arousal positive and negative adjectives (as in the case of PANAS), but is also extended to the range of low arousal emotions. Finally, just as PANAS, JAWS can potentially measure emotions as transient affective states and more stable affectivity.

The Job-related Affective Well-being Scale has a wide range of applications and is gaining popularity. For instance, according to Google Scholar, the article of Van Katwyk et al. [10] that introduced JAWS was cited 301 times (on 21th June 2014). An increasing trend of citation in scientific research is being observed. To date, JAWS has been used in the studies of various occupational groups such as administrative staff [12], healthcare personnel [13], transport employees [14], the general working population [15], managers [16], teams [17] and working couples [18]. Jobrelated Affective Well-being Scale is popular in the USA, the Netherlands, China, Canada, England, Switzerland, and Australia.

Recently, various non-English language versions of the scale have appeared, for instance in Dutch [19], Italian [12] and Slovenian [20]. However, some psychometric problems were encountered with these foreign language versions. Firstly, difficulties with translation of 
particular adjectives describing emotions arose [20]. Secondly, the factor structure did not correspond to that of the original version, which led to the exclusion of some items [19,21]. The most commonly used in Europe version of JAWS was developed in the Netherlands and it includes 12 items [19]. Using a sample of 815 employees, the 12- and 20-item versions of the scale showed good psychometric properties; for instance the hypothesized 4-factor structure was confirmed.

The original - 20-item scale has good internal consistency. The values of Cronbach's $\alpha$ coefficients varied between 0.80 and 0.90 in the original American version [10]. However, in European studies, the reliability of the original - 20-item JAWS was lower [19,20], whereas the reliability of the short, 12 -item, version was satisfactory (i.e., above 0.70$)[12,19]$.

\section{OBJECTIVES}

To date, no European study has used the multidimensional scaling procedure that was used in constructing the original version [10]. Such an approach, however, seems to be crucial when a circumplex model of emotion is assumed. In this model emotions are distributed in a circular shape, defined by 2 by 2 orthogonal axes: arousal and valence [22]. An exploratory factor analysis for circumplex matrix results in 2- or 3-factor solutions, which makes interpretation less straightforward [23]. Multidimensional scaling is an alternative here, as it extracts such a nonlinear structure directly from the data [24].

Therefore, the main objective of this study was to verify the a-priory 4-factor structure of the Polish version of JAWS, using both multidimensional scaling and confirmatory factor analysis. We chose to analyze 2 versions of the Job-related Affective Well-being Scale; the original - 20-item version [10] and the shortened - 12item version [19] because in organizational psychology short scales are preferred for economical reasons.

\section{MATERIAL AND METHODS}

\section{Participants and procedure}

Two calibration samples were used. The 1st one consisted of 395 sworn police officers (women constituted $15 \%$ of the group). The average tenure was 13.5 years $(\mathrm{SD}=5.4$, range: 1-30 years). The 2nd group consisted of 202 police recruits (22\% of women) in the 1 st year of duty. In Poland, $97 \%$ of police officers are less than 40 years old and $82 \%$ serve less than 20 years.

The current study was conducted during obligatory training for police recruits and facultative courses for sworn police officers in the Police Academy in 2011 and 2012, with the approval of the Commandant-Rector. Participation in the study was voluntary and anonymous. In accordance with ethical principles, after a written informed consent was obtained, the recruits and officers filled in the self-report questionnaires described below. Data were collected in groups at the end of the training sessions by a research assistant.

\section{Instrument}

The Polish version of the original 20-item JAWS was used to measure job-related affective states across the past month (30 days) [10]. This version of JAWS includes 2 dimensions: valence and arousal, which are used to assess 4 categories of emotions: low-arousal positive emotions (5 items, e.g., calm), high-arousal positive emotions (5 items, e.g., energetic), low-arousal negative emotions (5 items, e.g., bored) and high-arousal negative emotions (5 items, e.g., angry). Every item is scored on a 5-point scale, ranging from 1 - never to 5 - extremely often. Higher scores indicate more intense and more positive or negative affective reactions to the job.

Standardized, translated instruments are crucial to conducting cross-cultural research. However, there is no golden standard for translation methods. Despite the widely used Brislin's back-translation model, for successful translation a combination of translation methods 
is more and more popular [25,26]. As an alternative approach, an expert team approach with 2 independent translators was employed along with experienced researchers and professionals [27]. This method is useful when original instrument includes metaphorical and emotional terms [28,29].

In our study, Polish language version of the original, American, 20-item JAWS was prepared in an expert team approach. Two professional translators prepared the preliminary versions separately. Both translators possessed a very good command of Polish and English languages. In the case of equivalence between 2 translation versions, a translation of that adjective was accepted. In the case where different words were proposed, 2 clinical psychologists served as judges to make a final decision. Next, a pre-test in monolingual subjects (group of 30 fire-fighters) was provided to address potential translation and conceptual problems. Results revealed that one adjective should be improved. Afterwards, the final version was established.

\section{Statistical analysis}

Statistical analysis consisted of 2 steps. In the 1st step, the structure of Polish versions of the 20- and 12-item JAWS was investigated. A circumplex model of emotions was assumed and a multidimensional scaling procedure (ALSCAL) [23] with SPSS 20.0 was used. This allowed for placing each item in a 2-dimensional scatterplot, where the orthogonal axes are defined as valence and arousal. Two parameters were obtained: Kruskal's stress and $\mathrm{R}^{2}$. As a rule of thumb, values below 0.10 of Kruskal's stress are regarded as excellent, whereas values above 0.15 are considered unacceptable. An $\mathrm{R}^{2}$ of 0.80 is considered satisfactory for metric scaling [30].

The next step was to compare the goodness-of-fit of an ALSCAL-derived structure with the 20- and 12item JAWS by means of confirmatory factor analysis (CFA). Confirmatory factor analysis was performed by AMOS [31]. As suggested in literature [32], the factor models were evaluated with several goodness-of-fit indices. The $\mathrm{Chi}^{2}$ test, the Root Mean Square, Error of Approximation (RMSEA), the Normed Fit Index (NFI), the Tucker-Lewis Index (TLI) and the Comparative Fit Index (CFI) were applied accordingly. A model is assumed to fit the data reasonably well when RMSEA is below 0.08 and other indices are above 0.90 [33].

As 2 calibration samples were used, a multiple-group confirmatory factor analysis was also conducted with regard to the best-fitting models. To assess the invariance of the underlying factor structure, a hierarchy of more constrained models was tested. Due to the fact that such models are nested within less constrained ones, the $\mathrm{Chi}^{2}$ differencetest was used to test whether adding constraints significantly reduced the fit of the model.

\section{RESULTS}

\section{Descriptive analyses}

Table 1 presents the 20-item JAWS together with basic descriptive statistics for both calibration samples. As can be seen, during the past 30 days the participants experienced the whole spectrum of affective states at their work with different average intensity. Most of the items were normally distributed, with low values of skewness and kurtosis. Distribution of only a few items, all of them concerning negative emotions, measured in sample 2 departed from normality. However, these deviations can be regarded as acceptable.

\section{Exploration of structure}

To explore the dimensionality of job-related state-affect, the metric multidimensional scaling (ALSCAL) [23] was used, following the procedure implemented by van Katwyk et al. [10]. According to the theoretical assumptions, 2 dimensions - valence and arousal, were required. For such a model, the value for stress (Kruskal's stress formula 1) was a respectable 0.09 and the corresponding 
Table 1. Descriptive statistics of the 20-item Job-related Affective Well-being Scale (JAWS) on the 2 Polish samples

\begin{tabular}{|c|c|c|c|c|c|c|c|c|}
\hline \multirow{2}{*}{ Item } & \multicolumn{2}{|c|}{$\mathrm{M}$} & \multicolumn{2}{|c|}{ SD } & \multicolumn{2}{|c|}{ Skewness } & \multicolumn{2}{|c|}{ Kurtosis } \\
\hline & S1 & S2 & S1 & S2 & S1 & S2 & S1 & S2 \\
\hline Angry & 2.58 & 2.30 & 0.88 & 0.94 & 0.50 & 0.55 & 0.29 & 0.22 \\
\hline Anxious & 2.77 & 2.53 & 0.90 & 0.91 & 0.20 & 0.39 & -0.25 & 0.24 \\
\hline At ease & 2.66 & 3.20 & 0.97 & 0.95 & 0.29 & -0.19 & -0.50 & -0.42 \\
\hline Bored & 2.36 & 2.19 & 0.95 & 0.91 & 0.37 & 0.59 & -0.31 & 0.06 \\
\hline Calm & 3.06 & 3.52 & 0.99 & 0.98 & -0.19 & -0.60 & -0.45 & -0.04 \\
\hline Content & 3.28 & 3.97 & 0.84 & 0.74 & -0.21 & -0.55 & -0.22 & 0.80 \\
\hline Depressed & 2.38 & 2.03 & 0.91 & 0.96 & 0.53 & 1.04 & -0.18 & 1.03 \\
\hline Discouraged & 2.70 & 2.12 & 1.01 & 0.98 & 0.27 & 0.96 & -0.60 & 0.75 \\
\hline Disgusted & 2.66 & 2.10 & 1.03 & 0.96 & 0.29 & 0.61 & -0.49 & -0.22 \\
\hline Ecstatic & 2.32 & 3.39 & 0.98 & 0.97 & 0.40 & -0.30 & -0.39 & -0.19 \\
\hline Energetic & 3.53 & 4.07 & 0.80 & 0.80 & -0.28 & -0.73 & 0.20 & 0.94 \\
\hline Enthusiastic & 3.05 & 3.85 & 0.95 & 0.87 & 0.05 & -0.63 & -0.47 & 0.56 \\
\hline Excited & 2.77 & 3.73 & 0.88 & 0.96 & 0.31 & -0.55 & -0.13 & -0.03 \\
\hline Fatigued & 3.19 & 3.08 & 0.97 & 1.11 & 0.08 & -0.03 & -0.63 & -0.76 \\
\hline Frightened & 1.86 & 1.82 & 0.89 & 0.97 & 0.99 & 1.20 & 0.77 & 1.12 \\
\hline Furious & 2.30 & 1.78 & 1.01 & 0.89 & 0.62 & 0.92 & 0.06 & 0.17 \\
\hline Gloomy & 2.15 & 1.70 & 0.91 & 0.81 & 0.60 & 1.10 & 0.06 & 1.10 \\
\hline Inspired & 2.61 & 3.24 & 0.95 & 0.95 & -0.01 & -0.26 & -0.52 & -0.27 \\
\hline Relaxed & 2.56 & 3.26 & 0.96 & 0.94 & 0.13 & -0.37 & -0.50 & -0.04 \\
\hline Satisfied & 2.97 & 3.88 & 0.90 & 0.81 & -0.07 & -0.39 & -0.11 & 0.00 \\
\hline
\end{tabular}

$\mathrm{S} 1$ - sample $1(\mathrm{~N}=395) ; \mathrm{S} 2$ - sample $2(\mathrm{~N}=202)$.

$\mathrm{M}$ - mean; SD - standard deviation.

$\mathrm{R}^{2}$ was 0.98 [30]. Taken together this indicates a very satisfactory fit.

The results are plotted in Figure 1. As can be seen, horizontal dimension can be described as valence (high-low pleasure) and vertical dimension as arousal (high-low arousal). Compared to the negative emotion items, the positive emotion items are more coherent and symmetric towards the valence axis. For the negative emotions, when compared to distances between other consecutive points, the item 'bored' has the greatest distance from the adjacent items. Therefore, this item was removed from the model, which resulted in a small improvement of fit indices (Kruskal's stress $=0.08$ and $\mathrm{R}^{2}=0.99$ ) and a more circular shape.

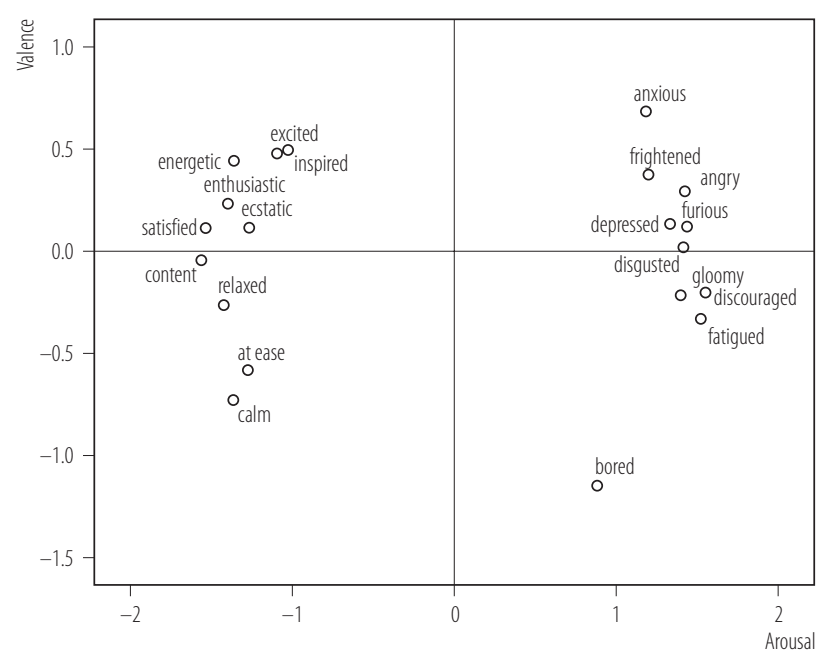

Fig. 1. Plots of 2-dimensional solutions from the multidimensional scaling of the Job-related Affective Well-being Scale (JAWS) ratings 


\section{Confirmation of structure}

In the next step, the confirmatory factor analysis (CFA) was used to verify the 4-factor structure adopted directly from the original 20 - and 12 -item versions as well as the 4-factor structure derived on the basis of multidimensional scaling. Table 2 displays the goodness-offit statistics for a series of CFA analyses. Error terms were uncorrelated and their variances were freed. Each time, the originally assumed structure was compared with the corresponding structure obtained by ALSCAL, where items were assigned to the subscales on the basis of their location in a 2-dimensional model, starting from the highest absolute values. As stated earlier, the 19-item ALSCAL model resulted after the removal of the 'bored' item.

The 12-item model [19], showed the best fit. As this exceeded the fit of the corresponding ALSCAL-based model, its dimensionality was tested. Results of multidimensional scaling showed that the solution, albeit clearly 2-dimensional (Kruskal's stress $=0.08 ; \mathrm{R}^{2}=0.98$ ), did

Table 2. Goodness of fit statistics for tests of factorial validity for different versions of the Job-related Affective Well-being Scale (JAWS)

\begin{tabular}{|c|c|c|c|c|c|c|c|}
\hline No. & Model & $\mathrm{Chi}^{2}$ & $\mathrm{df}$ & RMSEA & NFI & TLI & $\mathrm{CFI}$ \\
\hline & First calibration sample $(\mathrm{N}=395)$ & & & & & & \\
\hline 1 & 20-item original ${ }^{\mathrm{a}}$ & 625.62 & 164 & 0.09 & 0.87 & 0.89 & 0.90 \\
\hline 2 & 19-item ALSCAL & 610.19 & 146 & 0.09 & 0.86 & 0.87 & 0.89 \\
\hline 3 & 12-item original ${ }^{\mathrm{b}}$ & 175.07 & 48 & 0.08 & 0.93 & 0.93 & 0.95 \\
\hline 4 & 12-item ALSCAL & 193.99 & 48 & 0.09 & 0.91 & 0.91 & 0.93 \\
\hline \multirow[t]{2}{*}{5} & 8-item mixed ${ }^{c}$ & 30.83 & 14 & 0.06 & 0.97 & 0.97 & 0.99 \\
\hline & Second calibration sample $(\mathrm{N}=202)$ & & & & & & \\
\hline 6 & 20-item original ${ }^{\mathrm{a}}$ & 407.50 & 164 & 0.09 & 0.82 & 0.86 & 0.88 \\
\hline 7 & 19-item ALSCAL & 335.37 & 146 & 0.08 & 0.84 & 0.88 & 0.90 \\
\hline 8 & 12-item original ${ }^{\mathrm{b}}$ & 136.26 & 48 & 0.08 & 0.86 & 0.86 & 0.90 \\
\hline 9 & 12-item ALSCAL & 141.53 & 48 & 0.09 & 0.87 & 0.88 & 0.91 \\
\hline \multirow[t]{2}{*}{10} & 8-item mixed ${ }^{c}$ & $15.57^{*}$ & 14 & 0.02 & 0.97 & 0.99 & 1.00 \\
\hline & Multiple group analyses $(\mathrm{N}=395$ and $\mathrm{N}=202)$ & & & & & & \\
\hline 11 & 12-item original ${ }^{\mathrm{b}}$ (configural invariance) & 301.21 & 96 & 0.06 & 0.92 & 0.92 & 0.94 \\
\hline 12 & 12-item original (metric invariance) & 331.80 & 104 & 0.06 & 0.92 & 0.92 & 0.94 \\
\hline 13 & 12-item original ${ }^{b}$ (structural covariance invariance) & 345.70 & 114 & 0.06 & 0.91 & 0.93 & 0.94 \\
\hline 14 & $\begin{array}{l}\text { 12-item original }{ }^{b} \text { (structural covariance and unique variance } \\
\text { invariance) }\end{array}$ & 391.36 & 126 & 0.06 & 0.90 & 0.92 & 0.93 \\
\hline 15 & 8-item mixed (configural invariance) & 46.41 & 28 & 0.03 & 0.97 & 0.98 & 0.99 \\
\hline 16 & 8-item mixed (metric invariance) & 48.52 & 32 & 0.03 & 0.97 & 0.98 & 0.99 \\
\hline 17 & 8-item mixed ${ }^{c}$ (structural covariance invariance) & 61.78 & 42 & 0.03 & 0.96 & 0.98 & 0.99 \\
\hline 18 & $\begin{array}{l}\text { 8-item mixed (structural covariance and unique variance } \\
\text { invariance) }\end{array}$ & 86.86 & 50 & 0.04 & 0.95 & 0.98 & 0.98 \\
\hline
\end{tabular}

ALSCAL - assumed and a multidimensional scaling procedure; $\mathrm{Chi}^{2}$ - the Chi-square test; $\mathrm{df}$ - degree of freedom; RMSEA - the Root Mean Square Error of Approximation; NFI - the Normed Fit Index; TLI - the Tucker-Lewis Index; CFI - the Comparative Fit Index.

${ }^{a}$ According to Van Katwyk et al. [10]; ${ }^{b}$ according to Schaufeli and Van Rhenen [19]; ${ }^{c}$ the newest model was derived from reduction of the 12 -item JAWS. All $\mathrm{Chi}^{2}$ values except the one marked with * are significant at $\mathrm{p}<0.05$. 
Table 3. Cronbach's $\alpha$ for subscales of different versions of the Job-related Affective Well-being Scale (JAWS)

\begin{tabular}{|c|c|c|c|c|c|c|c|c|c|}
\hline \multirow{3}{*}{ Subscale } & \multicolumn{3}{|c|}{20 -item version ${ }^{\mathrm{a}}$} & \multicolumn{3}{|c|}{ 12-item version ${ }^{\mathrm{b}}$} & \multicolumn{3}{|c|}{ 8-item version ${ }^{c}$} \\
\hline & \multirow{2}{*}{ items } & \multicolumn{2}{|c|}{$\alpha$} & \multirow{2}{*}{ items } & \multicolumn{2}{|c|}{$\alpha$} & \multirow{2}{*}{ items } & \multicolumn{2}{|c|}{$\alpha$} \\
\hline & & S1 & $\mathrm{S} 2$ & & $\mathrm{~S} 1$ & S2 & & S1 & S2 \\
\hline $\begin{array}{l}\text { High Pleasure / High } \\
\text { Arousal }\end{array}$ & $\begin{array}{l}\text { excited } \\
\text { energetic } \\
\text { inspired } \\
\text { ecstatic } \\
\text { enthusiastic }\end{array}$ & 0.87 & 0.85 & $\begin{array}{l}\text { excited } \\
\text { energetic } \\
\text { inspired }\end{array}$ & 0.81 & 0.79 & $\begin{array}{l}\text { excited } \\
\text { energetic }\end{array}$ & 0.66 & 0.89 \\
\hline High Pleasure / Low Arousal & $\begin{array}{l}\text { at ease } \\
\text { relaxed } \\
\text { satisfied } \\
\text { content } \\
\text { calm }\end{array}$ & 0.88 & 0.85 & $\begin{array}{l}\text { at ease } \\
\text { relaxed } \\
\text { satisfied }\end{array}$ & 0.82 & 0.77 & $\begin{array}{l}\text { at ease } \\
\text { relaxed }\end{array}$ & 0.78 & 0.82 \\
\hline Low Pleasure / High Arousal & $\begin{array}{l}\text { angry } \\
\text { anxious } \\
\text { disgusted } \\
\text { frightened } \\
\text { furious }\end{array}$ & 0.83 & 0.80 & $\begin{array}{l}\text { angry } \\
\text { anxious } \\
\text { disgusted }\end{array}$ & 0.75 & 0.69 & $\begin{array}{l}\text { angry } \\
\text { anxious }\end{array}$ & 0.66 & 0.66 \\
\hline Low Pleasure / Low Arousal & $\begin{array}{l}\text { fatigued } \\
\text { discouraged } \\
\text { gloomy } \\
\text { depressed } \\
\text { bored }\end{array}$ & 0.82 & 0.74 & $\begin{array}{l}\text { fatigued, } \\
\text { discouraged } \\
\text { gloomy }\end{array}$ & 0.80 & 0.64 & $\begin{array}{l}\text { fatigued } \\
\text { discouraged }\end{array}$ & 0.71 & 0.52 \\
\hline
\end{tabular}

$\alpha$ - Cronbach's alpha coefficient.

a, b, c As in Table 2 .

S1, S2 - as in Table 1.

not reproduce the subscale structure sufficiently. JAWS is designed to differentiate between affective states of different valence and different levels of arousal. Therefore, items located close to zero on the horizontal dimension were removed because of their low discriminative power. Thus, finally, an 8-item model emerged. This emerged by reducing the 12-item JAWS (Model 5, Table 2) by 2 items per subscale (for details see Table 3 ). The resulting model with 8-itmes appeared to fit the data best.

The next step was to cross-validate the obtained results in the 2 nd, independent calibration sample. Again, 5 models were tested: 2 were based on the JAWS versions, 2 were based on ALSCAL solutions and there was the newly developed 8-item version. As can be seen in the 2nd panel of Table 2, the same models as before achieved the most satisfactory goodness-of-fit, with the 8-item model having the best fitness indices $\left(\mathrm{Chi}^{2}(14)=15.6, \mathrm{p}=0.34\right)$. Hence, in a multiple-group analysis only 2 models were taken into account, namely the 12-item and the 8-item JAWS.

In a series of CFAs, progressively more stringent forms of factorial invariance were tested, starting from configural invariance, defined as the same pattern of factor loadings and other parameters across groups, but without equality constraints [34].

The simultaneous fit of the 12-item solution was tested in Model 11, which achieved a reasonable fit to the data. Model 12 assumed factor loadings to be invariant across the groups. Although the indices mostly showed a comparable fit, this model appeared to deteriorate significantly with respect to the previous one $\left(\Delta \mathrm{Chi}^{2}(8)=30.6, \mathrm{p}<0.001\right)$. 
Further examination suggests that the lack of equality noted for some factor loadings can be attributed to socio-demographic differences between the samples. For instance, the biggest discrepancy was obtained for the item 'My job made me feel satisfied.' This item had a loading of 0.82 on the high pleasure/low arousal factor for the experienced police officers compared to 0.61 for the police recruits. Thus, in this light, there is no rationale for testing models assuming more stringent forms of factorial invariance.

Analogical analyses were performed for the 8-item model and resulted in a clearer pattern of results. Namely, a very good fit was obtained for Model 15, assuming configural invariance. Model 16, tested for invariance of factor loadings, also achieved a very good fit, this time without a significant deterioration compared to the previous model $\left(\Delta \mathrm{Chi}^{2}(4)=2.1, \mathrm{p}=0.72\right)$. The next 2 models were nested within the metric invariance model. Model 17, with equality of covariances as additional constraints, did not fit significantly worse $\left(\Delta \operatorname{Chi}^{2}(10)=13.3, p=0.21\right)$; which was, however, the case for Model 18, which assumed constant unique variances across the groups $\left(\Delta \mathrm{Chi}^{2}(8)=25.1\right.$, $\mathrm{p}=0.002$ ). For Model 17 the standardized factor loadings for the best fitting ranged from 0.60 to 0.84 and were all statistically significant at $\mathrm{p}<0.001$.

\section{Reliability analyses}

Table 3 displays Cronbach's $\alpha$ for the 20-, 12- and 8 -item versions of JAWS, obtained in both calibration samples. Values of internal consistencies range from acceptable to satisfactory. Generally speaking, reliability is lower for items with negative valence.

\section{DISCUSSION}

The aim of the current study was to test psychometric properties of the Polish version of the Job-related Affective Well-being Scale. Specifically, the 4-factor structure of JAWS and its reliability were investigated. The results of the analyses showed that the full spectrum of emotions was used, and that the circular shape, that is assumed by the underlying circumplex model, was reproduced. The 4-factor structure of JAWS was confirmed for the: 20-, 12-, and 8 -item versions. The original 20 -item JAWS had acceptable fit, and the 12-item JAWS had a good fit. The best results, however, were obtained for the 8-item JAWS. Finally, exact replication of JAWS in both samples was not obtained The reliability of the 20- and 12 -item versions was good, whereas for the 8-item version the reliability was weaker - but still sufficient.

Both samples of the participants experienced the whole spectrum of job-related affective states. The adjectives 'energetic' (high arousal) and 'calm' (low arousal) were the most frequently experienced among the positive emotions, while among negative emotions 'fatigued' (low arousal) was the most often observed one. Based on the theoretical assumptions [9,10], the 19-item version reproduced the circular shape better than the 20-item JAWS. Multidimensional scaling showed that the adjective 'bored' was far away from other low arousal displeasure emotions and should, therefore, be removed. After this removal, fit indices for the 19-item version improved. The same problem was encountered with the adjective 'bored' in a Slovenian validity study of the 30-item version of JAWS [20]. In a similar vein, Guerrero and Herrbach [35] have found in a sample of French-speaking Canadians that the boredom item constituted a separate factor, independently from the positive and negative emotion factors. Hence, it seems that the emotion of 'boredom' does not fit well into the hypothesized circumplex model, irrespective of which language version of JAWS is used.

The 4-factor structure of the 20-, 12- and 8-item versions of JAWS was confirmed. Results showed that both dimensions, valence and arousal, are necessary in order to describe job-related emotions. In our study, both versions had acceptable fit to the data, whereby the 12-item JAWS [19] had better fit than the 20-item version [10]. This demonstrates that these versions are quite similar across 
languages and cultures, but also that some discrepancies cannot be avoided due to cultural and linguistic differences. For instance, it must be noted that the expression of complex emotions (e.g., satisfaction), more than basic emotions (e.g., anger), varies significantly across languages and cultures [36]. This phenomenon is also described in emic - etic distinction [37], which reflects that certain differences (emic) and certain similarities (etic) are always present in theories and methods when studied from a cross-cultural perspective. Therefore, it is not surprising that some differences are observed in the JAWS adaptations but they are still justified by the nature of the operationalized construct itself. Thus, both 20- and 12-item versions of JAWS can be recommended.

Our results also showed that an alternative 8-item version, which resulted from removing 4 items from the 12item JAWS, reflected the best structure of our empirical data. This model was replicated successfully in both samples. According to the literature, only one 8-item shortened form of JAWS has been used [21]. However, it must be noted that this 8-item version of the Job-related Affective Well-being Scale contains different items than our version. Again, it is possible that this reveals an emic distinction [37]. Testing of the 2 best fitted models in 2 samples revealed that the factor loadings were not fully invariant across both samples. It is likely that this was caused by sociodemographic differences between both samples, for instance, in age and occupational experience. The biggest discrepancy was observed with regard to the adjective 'satisfied.' In the group of experienced police officers, satisfaction from work is associated with the policing profession, but in the sample of recruits, satisfaction is related to occupational training, not real police work.

Testing the 8-item JAWS model with equality of covariances achieved a reasonable fit to the data. It is often the case that highly constrained models, for example those assuming constant unique variances across groups, are not confirmed. This is most likely so because error variances may differ from one group to another as this reflects the heterogeneity of samples. It is becoming increasingly evident that the study of affective states, not traits, may depend on the context and characteristics of the group [38]. The results of our reliability analyses showed that the values for internal consistencies were better for subscales consisting of more rather than fewer items. These were also higher for subscales of pleasure than for subscales of displeasure. In the previous studies $[19,20]$ the original 20-item JAWS had much weaker internal coefficients than in the presented study. The 8-item version of JAWS used by Balducci et al. [21] also showed lower values, sometimes even below 0.60 , whereas the 12-item JAWS consistently reached values of these coefficients above 0.70 . This is rather typical when Cronbach's $\alpha$ is used with shortened versions of the same scale as the value of this coefficient depends on the length of the scale [39].

\section{Limitations}

Our study has some limitations. Firstly, it focused on the policing profession only. In this group, women are much less represented than in the general population of employees. This means that the generalizability of our results is probably limited and that future research using other occupational groups is necessary. In future studies a more general population of employees should be examined. A particular attention could be paid to the customer service sector, in the case of which repetitive but mentally demanding work is posted. Also focus on occupational groups of unstable and uncertain conditions (e.g., temporary contract, irregular working hours) should be taken into account. Nowadays this issue is especially important due to changes in a labour market, resulting in unemployment and constantly increasing self-employment. To sum up, replication of research among other professional groups is needed.

Secondly, affective state was not studied in real time, but as a retrospective self-report. Two new research methods: the Experience Sampling Method and the Day Reconstruction 
Method can be proposed [40]. These methods support measurement of the momentary affective well-being of individuals as a reaction to dynamics of a work environment. Also they can examine the fluctuation within person depending on events and social reaction during the workday. Such methodological approach is crucial for advancing knowledge and practice in the field of organizational and occupational health psychology.

Finally, discriminant validity of the 4 subscales requires confirmation. Thus, although presented data provide a preliminary support for the structure validity and internal reliability, the JAWS ecological validity, crucial for scales assessing momentary affect, still needs further investigation.

\section{CONCLUSIONS}

Despite these shortcomings, the results of our study revealed that in order to assess job-related emotions, 2 dimensions: valence and arousal, should be included. Both the 12-item JAWS and the 20-item JAWS may be recommended. The 8-item JAWS showed the best fit to the theoretical model but, at the same time, this version had lower internal consistency. Thus, if both aspects of the psychometric properties are considered, the 12-item JAWS seems to be the primary choice unless a shortened version is preferred. The 8-item version of JAWS could be especially useful in procedures where smaller number of items is advantageous (e.g., online or "day-by-day" assessment). However, it must be emphasized that every survey of affective states is contaminated by the moment and context in which it is conducted. If these limitations are borne in mind, the 4-factor structure of job-related affective well-being may be successfully applied in organizational research.

\section{ACKNOWLEDGMENTS}

The authors would like to thank Izabela Wiciak for data collection.

\section{REFERENCES}

1. Folkman $\mathrm{S}$. The case for positive emotions in the stress process. Anxiety Stress Coping. 2008;21(1):3-14, http://dx.doi. org/10.1080/10615800701740457.

2. Maslach C, Schaufeli WB, Leiter MP. Job burnout. Ann Rev Psychol. 2001;52(1):397-422, http://dx.doi.org/10.1146/ annurev.psych.52.1.397.

3. Schaufeli WB. What is engagement? In: Truss C, Delbridge R, Alfes K, Shantz A, Soane E, editors. Employee engagement in theory and practice. London: Routledge; 2014. p. 15-35.

4. Warr P, Bindl UK, Parker SK, Inceoglu I. Four-quadrant investigation of job-related affects and behaviours. Eur J Work Organ Psychol. 2014;23(3):342-63, http://dx.doi.org/10.1080/ 1359432X.2012.744449.

5. Alonso-Arbiol I, van der Vijver FJR. A historical analysis of the European Journal of Psychological Assessment: A comparison of the earliest (1992-1996) and the latest years (2005-2009). Eur J Psychol Assess. 2010;26(4):238-47, http://dx.doi.org/10.1027/1015-5759/a000032.

6. Brough P, Dollard MF, Tuckey MR. Theory and methods to prevent and manage occupational stress: Innovations from around the globe. Int J Stress Manage. 2014;21(1):1-6, http://dx.doi.org/10.1037/a0035903.

7. Lesage FX, Berjot S, Deschamps F. Psychometric properties of the French versions of the Perceived Stress Scale. Int J Occup Med Environ Health. 2012;25(2):178-84, http:// dx.doi.org/10.2478/S13382-012-0024-8.

8. Russell JA, Carroll JM. On the bipolarity of positive and negative affect. Psychol Bull. 1999;125(1):3-30, http://dx.doi. org/10.1037/0033-2909.125.1.3.

9. Warr P. The measurement of well-being and other aspects of mental health. J Occup Psychol. 1990;63(3):193-210, http:// dx.doi.org/10.1111/j.2044-8325.1990.tb00521.x.

10. Van Katwyk PT, Fox S, Spector PE, Kelloway EK. Using the job-related affective well-being scale (JAWS) to investigate affective responses to work stressors. J Occup Health Psychol. 2000;5(2):219-30, http://dx.doi.org/10.1037/10768998.5.2.219. 
11. Watson D, Clark LA, Tellegen A. Development and validation of brief measures of positive and negative affect: The PANAS scales. J Pers Soc Psychol. 1988;54(6):1063-70, http://dx.doi.org/10.1037/0022-3514.54.6.1063.

12. Balducci C, Fraccaroli F, Schaufeli WB. Psychometric properties of the Italian version of the Utrecht Work Engagement Scale (UWES-9): A cross-cultural analysis. Eur J Psychol Assess. 2010;26(2):143-9, http://dx.doi.org/10.1027/ 1015-5759/a000020.

13. Uncu Y, Bayram N, Bilgel N. Job related affective wellbeing among primary health care physicians. Eur J Public Health. 2007;17(5):514-9, http://dx.doi.org/10.1093/eurpub/ ckl264.

14. Machin MA, Hoare PN. The role of workload and driver coping styles in predicting bus drivers' need for recovery, positive and negative affect, and physical symptoms. Anxiety Stress Coping. 2008;21(4):359-75, http://dx.doi. org/10.1080/10615800701766049.

15. Lubbers R, Loughlin C, Zweig D. Young workers' job selfefficacy and affect: Pathways to health and performance. J Vocat Behav. 2005;67(2):199-214, http://dx.doi.org/10.10 16/j.jvb.2004.03.002.

16. Kelloway EK, Turner N, Barling J, Loughlin C. Transformational leadership and employee psychological well-being: The mediating role of employee trust in leadership. Work Stress. 2012;26(1):39-55, http://dx.doi.org/10.1080/02678373. 2012.660774.

17. Cole MS, Walter F, Bruch H. Affective mechanisms linking dysfunctional behavior to performance in work teams: A moderated mediation study. J Appl Psychol. 2008;93(5): 945-58, http://dx.doi.org/10.1037/0021-9010.93.5.945.

18. Danner-Vlaardingerbroek G, Kluwer ES, van Steenbergen EF, van der Lippe T. Knock, knock, anybody home? Psychological availability as link between work and relationship. Pers Relationships. 2013;20(1):52-68, http://dx.doi. org/10.1111/j.1475-6811.2012.01396.x.

19. Schaufeli W, van Rhenen W. [About the role of positive and negative emotions in managers' wellbeing: A study using the
Job-related Affective Well-being Scale (JAWS)]. Gedrag Organ. 2006;19(4):323-44. Dutch.

20. Rode N. Translation of measurement instruments and their reliability: An example of Job-related Affective Well-being Scale. Adv Method Stat. 2005;2:15-26.

21. Balducci C, Cecchin M, Fraccaroli F, Schaufeli WB. Exploring the relationship between workaholism and workplace aggressive behaviour: The role of job-related emotion. Pers Individ Dif. 2012;53(5):629-34, http://dx.doi.org/10.1016/ j.paid.2012.05.004.

22. Russell JA. A circumplex model of affect. J Pers Soc Psychol. 1980;39:1161-78, http://dx.doi.org/10.1037/h0077714.

23. Davidson ML. Multidimensional scaling versus components analysis of test intercorrelations. Psychol Bull. 1995;97: 94-105, http://dx.doi.org/10.1037/0033-2909.97.1.94.

24. Weiner IB, Schinka JA, Velicer WF. Handbook of psychology. Research methods in psychology. Vol. 2. Hoboken, NJ: John Wiley \& Sons Inc.; 2003, http://dx.doi. org/10.1002/0471264385.

25. Cha ES, Kim KH, Erlen JA. Translation of scales in cross-cultural research: Issues and techniques. J Adv Nurs. 2007;58(4):386-95, http://dx.doi.org/10.1111/j.13652648.2007.04242.x.

26. Voss KE, Stem DE, Johnson LW, Arce C. An exploration of the comparability of semantic adjectives in 3 languages: A magnitude estimation approach. Int Market Rev. 1996; 13(5):44-58, http://dx.doi.org/10.1108/02651339610131388.

27. Netz Y, Zeav A, Arnon M, Daniel S. Translating a singleword items scale with multiple subcomponents - A Hebrew translation of the profile of mood states. Isr J Psychiatry Relat Sci. 2005;42(4):263-70.

28. Kayyal MH, Russell JA. Language and emotion: Certain English-Arabic translations are not equivalent. J Lang Soc Psychol. 2013;32(3):261-71, http://dx.doi.org/10.1177/ $0261927 X 12461004$.

29. Russell JA, Sato K. Comparing emotion words between languages. J Cross Cult Psychol. 1995;26(4):384-91, http:// dx.doi.org/10.1177/0022022195264004. 
30. Kruskal JB, Wish M. Multidimensional scaling. Beverly Hills, London: Sage Publications; 1978.

31. Arbuckle JL. AMOS 18.0 [computer software]. Chicago: SPSS; 2007.

32. Bollen KA, Long JS. Testing structural equation models. Newbury Park CA: Sage; 1993.

33. Byrne BM. Structural equation modeling with AMOS: Basic concepts, applications, and programming. 2nd ed. New York: Taylor and Francis Group; 2010.

34. Vandenberg RJ, Lance CE. A review and synthesis of the measurement invariance literature: Suggestions, practices, and recommendations for organizational research. Organ Res Methods. 2000;3:4-69, http://dx.doi.org/10.1177/109442810031002.

35. Guerrero S, Herrbach $\mathrm{O}$. The affective underpinnings of psychological contract fulfilment. J Manag
Psychol. 2008;23(1):4-17, http://dx.doi.org/10.1108/0268394 0810849639.

36. Ekman P. Are there basic emotions? Psychol Rev. 1992; 99(3):550-3, http://dx.doi.org/10.1037/0033-295X.99.3.550.

37. Berry JW. Imposed etics-emics-derived etics: The operationalization of a compelling idea. Int J Psychol. 1989;24(6):721-35, http://dx.doi.org/10.1080/0020759890 8247841.

38. Yik M. Culture, gender, and the bipolarity of momentary affect. Cognition Emotion. 2007;21(3):664-80, http://dx.doi. org/10.1080/02699930600823702.

39. Nunnally J. Psychometric theory. New York: McGrawHill; 1978.

40. Bakker AB, Daniels K, editors. A day in the life of a happy worker. Hove Sussex: Psychology Press; 2013.

This work is available in Open Access model and licensed under a Creative Commons Attribution-NonCommercial 3.0 Poland License - http://creativecommons.org/ licenses/by-nc/3.0/pl/deed.en. 